\title{
Intemperismo artificial de quatro revestimentos aplicados em madeiras de duas espécies florestais
}

\author{
Aline Krolow SOARES ${ }^{1}$, Roberto Lessa PEREIRA², Pedro Henrique Gonzalez de \\ CADEMARTORI $^{3}$, Henrique Weber DALLA COSTA ${ }^{4}$, Darci Alberto GATTO ${ }^{1,2,4 *}$
}

\author{
${ }^{1}$ Programa de Pós-Graduação em Ciência e Engenharia de Materiais, Universidade Federal Pelotas, Pelotas, RS, Brasil. \\ ${ }^{2}$ Centro de Engenharias, Universidade Federal Pelotas, Pelotas, RS, Brasil. \\ ${ }^{3}$ Programa de Pós-Graduação em Engenharia e Ciência dos Materiais, Universidade Federal do Paraná, Curitiba, PR, Brasil. \\ ${ }^{4}$ Programa de Pós-Graduação em Engenharia Florestal, Universidade Federal de Santa Maria, Santa Maria, RS, Brasil. \\ *E-mail: darcigatto@yahoo.com
}

\begin{abstract}
Recebido em junho/2017; Aceito em outubro/2017.
RESUMO: O presente estudo teve como objetivo investigar a resistência ao intemperismo artificial de quatro revestimentos aplicados nas madeiras de duas espécies florestais. Para tal, foram utilizadas seis árvores de Eucalyptus grandis e três árvores de Tetrorchidium rubrivenium as quais foram desdobradas para confecção de

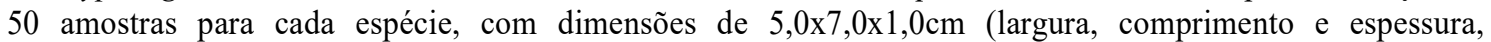
respectivamente). A superfície das madeiras foi revestida com quatro acabamentos: polistein, verniz marítimo, tinta branca base óleo e tinta branca base água. As amostras sem revestimento e revestidas foram submetidas ao ensaio de envelhecimento acelerado durante 480 horas. A resistência ao intemperismo artificial foi avaliada por meio das modificações colorimétricas e morfológicas ao longo da exposição das madeiras e em função da molhabilidade superficial. Os principais resultados mostraram que a superfície das madeiras tendeu a tons opacos após exposição de 480 horas. Foi observado que os revestimentos não evitaram o aumento da molhabilidade superficial. Após todo o período de exposição, as madeiras não apresentaram modificações morfológicas tais como rachaduras e descascamento dos revestimentos, o que denota importante característica de proteção à madeira.
\end{abstract}

Palavras-chave: Eucalyptus, canemaçu, modificação da superfície, envelhecimento acelerado, durabilidade da madeira.

\section{Artificial weathering of four coatings applied on woods of two forest species}

\begin{abstract}
The present study aimed to investigate the resistance to artificial weathering of four coatings applied on wood from two forest species. Six trees of Eucalyptus grandis and three trees of Tetrorchidium rubrivenium were cut to produce 50 wood samples for each species with dimensions of $5.0 \times 7.0 \times 1.0 \mathrm{~cm}$ (width, length and thickness, respectively). Wood surface was coated with four finishing products: polistein, marine varnish, oil-based white paint and water-based white paint. The uncoated and coated wood samples were subjected to accelerated aging test for $480 \mathrm{~h}$. The artificial weathering resistance was evaluated by color changes and surface wettability. The main results showed the coated woods tend to opaque tones after the exposure for 480h. The coatings did not avoid the increase of the surface wettability. After the exposure, both woods did not present morphological changes, such as cracks and peeling into the coatings, which represent relevant characteristics for wood protection.
\end{abstract}

Keywords: Eucalyptus, canemaçu, surface modification, accelerated aging, wood durability.

\section{INTRODUÇÃO}

A madeira é um material renovável com ampla aplicação no setor industrial devido as suas propriedades versáteis e atraentes (YENIOCAK et al. 2015). Porém, por ser de origem orgânica, é facilmente deteriorada quando exposta às intempéries. Em muitas situações, a exposição desse material não tratado em ambientes propícios à degradação deve-se ao desconhecimento em relação aos tipos de tratamentos superficiais existentes ou até mesmo por livre escolha do consumidor final (CADEMARTORI et al., 2015).

A intensidade de sua degradação depende da combinação de fatores físicos e químicos encontrados na natureza, tais como luz solar, umidade, temperatura, oxigênio, poluentes atmosféricos, abrasão e fatores biológicos (GRULL et al., 2014; YILDIZ et al., 2013). Quando exposta à ação desses agentes, a madeira apresenta perda de suas características naturais - cor, brilho e textura - em função da modificação superficial.

As modificações colorimétricas ocorrem inicialmente pela perda de brilho e rugosidade (LESAR et al., 2011) devido a ação da luz UV solar combinada com a umidade, a temperatura e a oxidação (ROSU et al., 2010). Estes agentes causam a despolimerização da lignina e dos carboidratos presentes na parede celular da madeira (ARANTES; MILAGRES, 2009; GRULL et al., 2014).

A lignina é o componente químico da parede celular da madeira mais susceptível às intempéries, principalmente a luz UV (QIAN et al., 2017). A lignina é capaz de absorver entre 80 e $95 \%$ de radiação solar devido a presença de grupos fenólicos em sua estrutura molecular (LESAR et al., 2011; 
POLETTO et al., 2017). Simultaneamente ao efeito na aparência, determinadas características físicas e morfológicas podem ser afetadas, tais como molhabilidade e presença de micro rachaduras (CHANG et al., 2010). A influência significativa do intemperismo no aumento da molhabilidade superficial foi observada em estudos anteriores para madeira de folhosas (CADEMARTORI et al., 2015) e madeira de coníferas (OBERHOFNEROVÁ; PÁNEK, 2016).

Para evitar a degradação superficial dos produtos de madeira em ambientes externos são aplicados revestimentos que devem cumprir uma série de funções específicas para proteger o substrato de madeira (GRULL et al., 2011). Os produtos comerciais de acabamento são utilizados com a função de revestir a superfície da madeira, permitindo a preservação aparente do material quando em serviço, além de auxiliar em questões de cunho estético (GRULL et al., 2014).

Cada um dos produtos de acabamento possui características técnicas bem definidas quanto ao tipo de material em que deve ser aplicado e os métodos de aplicação, bem como a durabilidade do revestimento quando exposto em ambientes internos e/ou externos (WILLIAMS, 2010). No entanto, esses revestimentos também estão sujeitos a degradação pela ação de intempéries, uma vez que a luz UV e a umidade são prejudiciais para os polímeros aglutinantes de revestimentos, e a exposição por longos períodos leva a um aumento da fragilidade, aparecimento de rachaduras e descamação do revestimento (GRULL et al., 2011). Dessa maneira, o verniz apresenta uma maior eficiência na preservação das características originais da madeira em comparação com o stain quando aplicado em madeiras tropicais (SILVA et al., 2006). Por outro lado, os sistemas opacos de revestimento (tintas brancas) apresentam maior durabilidade quando expostos ao intemperismo (GRULL et al., 2011)

Além disso, as propriedades intrínsecas do substrato, tais como permeabilidade, plasticidade, reatividade química e porosidade também devem ser consideradas. Isso porque ao longo do tempo a durabilidade dos revestimentos é geralmente distinta em comparação a vida útil dos componentes da madeira. A durabilidade dos revestimentos é influenciada por uma variedade de fatores, em que a formulação do revestimento, a espessura do filme, a pigmentação, o uso de estabilizadores de luz, propriedades e design do substrato, bem como as condições de exposição desempenham os papéis mais importantes (WILLIAMS, 2010; GLULL et al., 2011; GRULL et al., 2014).

Existe grande interesse em soluções que reduzam o efeito das intempéries na madeira (LESAR et al., 2011), aumentando sua durabilidade e mantendo suas propriedades originais. No entanto, a literatura científica carece de estudos que comprovem a resistência de vernizes e tintas aplicados na madeira após longos períodos de exposição. Portanto, o presente estudo investigou o efeito da proteção de quatro produtos de acabamento nas madeiras de Eucalyptus grandis Hill ex Maiden e Tetrorchidium rubrivenium Poepp. \& Endl. submetidas a ação de intemperismo artificial. A cor e a molhabilidade superficial foram os parâmetros adotados para mensurar o grau de modificação da superfície das madeiras após um ciclo total de 480 horas de exposição.

\section{MATERIAL E MÉTODOS}

\subsection{Seleção e preparo do material}

A madeira utilizada no presente estudo proveio de seis árvores de E. grandis com 17 anos de idade, plantadas em um povoamento localizado na cidade de Capivari do Sul $\left(30^{\circ} 08^{\prime} 42^{\prime \prime} \mathrm{S}, 50^{\circ} 30^{\prime} 53^{\prime \prime} \mathrm{O}\right)$ (RS, Brasil) e três árvores de $T$. rubrivenium (canemaçu) coletadas no Vale do Sol $\left(29^{\circ} 35^{\prime} 28^{\prime \prime} \mathrm{S}, 52^{\circ} 41^{\prime} 41^{\prime \prime} \mathrm{O}\right)$ (RS, Brasil), selecionadas ao acaso.

As tábuas oriundas do desdobro primário das toras foram selecionadas de maneira a não conter defeitos, tais como nós, rachaduras e empenamentos. A partir das tábuas, foram confeccionadas 50 amostras para cada espécie com

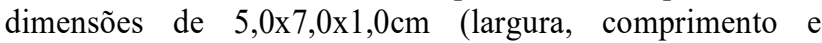
espessura, respectivamente). As amostras foram lixadas (lixa grão 50) na superfície de aplicação dos produtos de acabamento e acondicionadas em câmara climática com temperatura de $20 \pm 2^{\circ} \mathrm{C}$ e $65 \pm 5 \%$ de umidade relativa do ar até a obtenção do teor de umidade de equilíbrio, em torno de $12 \%$.

Posteriormente, as amostras foram revestidas com quatro produtos de acabamento: polistein (T1), verniz marítimo (T2), tinta branca base óleo (T3) e tinta branca base água (T4) (Tabela 1). As amostras controle (T0) não receberam quaisquer aplicações de produtos em sua superfície. Os revestimentos foram aplicados manualmente com um pincel em três demãos no plano longitudinal tangencial das amostras. A espessura final do revestimento foi de aproximadamente $4,5 \mu \mathrm{m}$. Após o revestimento, as amostras foram novamente acondicionadas em câmara climática nas mesmas condições supracitadas durante 48 horas.

Tabela 1. Informações técnicas dos produtos de acabamento utilizados no estudo.

Table 1. Technical information of the finishing products used in the study.

\begin{tabular}{|c|c|}
\hline \multirow{2}{*}{\multicolumn{2}{|c|}{ tein* }} \\
\hline & \\
\hline Densidade & $0,88 \pm 0,02$ g.cm $\mathrm{cm}^{-3}$ \\
\hline Tempo de cura & 24 horas \\
\hline $\begin{array}{l}\text { Composição } \\
\text { química básica }\end{array}$ & $\begin{array}{l}\text { Polímero alquídico modificado, óleos vegetais, } \\
\text { hidrocarbonetos alifáticos e aromáticos, álcoois, } \\
\text { agentes tensoativos, secantes organo metálicos, } \\
\text { minerais inertes, pigmentos, agentes } \\
\text { bactericidas/fungicidas. }\end{array}$ \\
\hline \multicolumn{2}{|r|}{ Verniz Marítimo* } \\
\hline Densidade & $0,92 \pm 0,02 \mathrm{~g} \cdot \mathrm{cm}^{-3}$ \\
\hline Tempo de cura & 24 horas \\
\hline $\begin{array}{l}\text { Composição } \\
\text { química básica }\end{array}$ & $\begin{array}{l}\text { Polímero alquídico modificado, óleos vegetais, } \\
\text { hidrocarbonetos alifáticos e aromáticos, agentes } \\
\text { tensoativos, secantes organo metálicos. }\end{array}$ \\
\hline \multicolumn{2}{|r|}{ Tinta base água* } \\
\hline Densidade & $1,20 \pm 0,2 \mathrm{~g} \cdot \mathrm{cm}^{-3}$ \\
\hline Tempo de cura & 5 horas \\
\hline $\begin{array}{l}\text { Composição } \\
\text { química básica }\end{array}$ & $\begin{array}{l}\text { Polímero acrílico modificado, bactericidas e } \\
\text { fungicidas não metálicos, carbonato de cálcio, } \\
\text { dióxido de titânio, pigmentos orgânicos e } \\
\text { inorgânicos, éteres glicólicos, sais de sódio e } \\
\text { água. }\end{array}$ \\
\hline \multicolumn{2}{|r|}{ Tinta base óleo* } \\
\hline Densidade & $1,25 \pm 0,2$ g.cm ${ }^{-3}$ \\
\hline Tempo de cura & 24 horas \\
\hline $\begin{array}{l}\text { Composição } \\
\text { química básica }\end{array}$ & $\begin{array}{l}\text { Resina alquídica, pigmentos orgânicos e } \\
\text { inorgânicos, dióxido de titânio, secantes aditivos, } \\
\text { hidrocarbonetos alifáticos, silicato de alumínio. }\end{array}$ \\
\hline
\end{tabular}




\subsection{Ensaio de envelhecimento acelerado}

De cada 10 amostras confeccionadas para cada tratamento, oito foram submetidas ao ensaio de envelhecimento acelerado, enquanto que duas amostras foram retiradas ao acaso para permanecerem em câmara climática e representarem o tempo $0 \mathrm{~h}$ de exposição. $\mathrm{O}$ ensaio foi realizado em uma câmara de intemperismo artificial, modelo BASS-UV-STD-SPRAY-4400/2013, com radiação luminosa de $1,35 \mathrm{~W} / \mathrm{m}^{2} / \mathrm{nm}$, conforme procedimento descrito pela norma American Society for Testing and Materials ASTM G154 (2006). Cada ciclo simulado pela câmara representou os efeitos de degradação causados pela luz solar (8h na faixa do ultravioleta a $\left.60 \pm 3^{\circ} \mathrm{C}\right)$, chuva $(0,25 \mathrm{~h}$ de spray de água) e orvalho $\left(3,75 \mathrm{~h}\right.$ de condensação a $\left.50 \pm 3^{\circ} \mathrm{C}\right)$ na superfície das amostras. Foram realizados 40 ciclos, cada um com $12 \mathrm{~h}$ de duração, totalizando $480 \mathrm{~h}$ de exposição.

\subsection{Análise colorimétrica}

As modificações colorimétricas das madeiras foram mensuradas por meio de um colorímetro Konica Minolta (modelo CR-400) equipado com fonte iluminante D65, ângulo de observação de $10^{\circ}$ e abertura do sensor de $8 \mathrm{~mm}$, conforme o padrão CIE- $L * a * b *$. Foram realizadas três leituras nas amostras a cada dois ciclos de exposição. Com isso, obtiveram-se os parâmetros $L^{*}$ (luminosidade), $a^{*}$ (coordenada cromática vermelho-verde), $b^{*}$ (coordenada cromática amarelo-azul) e $C^{*}$ (saturação da cor).

\subsection{Molhabilididade}

A molhabilidade superficial das amostras foi avaliada antes e após o ensaio de envelhecimento acelerado (ciclos 0 e 40). Para tal, utilizou-se um goniômetro Krüss, modelo DSA25 configurado com o método de gota séssil. Para caracterizar os tratamentos, foram selecionadas ao acaso 5 amostras, sendo duas controle e três submetidas ao envelhecimento acelerado, totalizando 25 amostras para cada espécie. Três gotículas de água deionizada (volume de $5 \mu \mathrm{l}$ ) foram depositadas em três pontos distintos da superfície de cada amostra. O ângulo de contato aparente (CA) foi mensurado após $5 \mathrm{~s}$ de deposição da gotícula na superfície das amostras.

\subsection{Morfologia da superfície}

As modificações morfológicas do revestimento em função do tempo de exposição (0 e 480h) foram investigadas por meio de um estereomicroscópio Zeiss Discovery 1.0. As imagens de alta resolução foram capturadas com uso de lentes com aumento de $10 \mathrm{x}$ e utilizadas para identificar aspectos relacionados à fotodegradação, tais como descascamento, perda de brilho e surgimento de micro rachaduras na superfície do substrato revestido.

\subsection{Análise dos dados}

Os dados de CA aparente foram submetidos à análise de variância multifatorial, em que se avaliou o efeito dos fatores ciclo e tratamento isoladamente e a interação entre os mesmos. Quando se detectou rejeição da hipótese nula, as médias foram analisadas por meio do teste HSD de Tukey a $5 \%$ de probabilidade de erro $(\mathrm{p}<0,05)$.

\section{RESULTADOS}

\subsection{Análise colorimétrica}

O comportamento das curvas para a coordenada cromática vermelho-verde $\left(a^{*}\right)$ foi inverso no T0 para cada espécie, indicando que após a exposição a madeira de $T$. rubrivenium apresentou tonalidades de marrom enquanto que a madeira de $E$. grandis tornou-se acinzentada após o período de intemperismo artificial (Tabela 2). De maneira geral, após a aplicação dos revestimentos, as madeiras de ambas espécies apresentaram comportamento similar, ou seja, aumento dos valores de $a^{*}$ até certo ponto e posterior redução. Esse aumento teve variação entre os ciclos de 36 e $120 \mathrm{~h}$, conforme cada tratamento.

Para a coordenada cromática amarelo-azul $\left(b^{*}\right)$, somente T2 seguiu a tendência do T0, isto é, redução do parâmetro ao longo do período de exposição. Para os demais tratamentos (T1, T3 e T4), houve acréscimo inicial e posterior redução. Em T3 e T4 ocorreu oscilação do parâmetro $b^{*}$ até o período de exposição de $60 \mathrm{~h}$.

O parâmetro $L^{*}$ foi o que mais apresentou variação entre tratamento e espécies. Nos revestimentos T2, T3 e T4, ocorreu redução após as primeiras $12 \mathrm{~h}$ e aumento do parâmetro até $48 \mathrm{~h}$, seguido de redução até o final do período de exposição. Os tratamentos T0 e T1 diminuíram até o final do período de exposição na madeira de $T$. rubrivenium, enquanto que para o E. grandis ocorreu oscilação dos parâmetros até $48 \mathrm{~h}$ acompanhado de um aumento gradual em T0. Esse comportamento foi contrário ao observado em T1, onde houve oscilação de valores seguida de uma redução para o parâmetro $L^{*}$.

Os diagramas de cromaticidade $L^{*}$ x $C^{*}$ (Figuras 1 e 2) foram gerados com o intuito de identificar e confirmar as alterações de tonalidades previamente relatadas no trabalho. Para a madeira de E. grandis não tratada (T0) observou-se perda de luminosidade nos primeiros ciclos, tendendo para a região central do gráfico, característica de materiais opacos. Conforme o aumento do tempo de exposição, a tonalidade da madeira não tratada de $E$. grandis tendeu aos eixos representativos de tons acinzentados e muito claros. As madeiras revestidas com tinta branca à base de óleo (T3) e tinta branca à base de água (T4) não apresentaram alterações no diagrama de cromaticidade. Ambos os tratamentos se mantiveram com as tonalidades iniciais, classificadas no gráfico como muito clara. Em relação à madeira de $T$. rubrivenium, observa-se que em todos os tratamentos o comportamento da variação da tonalidade foi similar a madeira de E. grandis (Figura 2).

\subsection{Molhabilidade}

As análises de variância multifatorial (Tabela 3) apontaram que os fatores ciclo e tratamento foram significativos, além de interação entre os dois fatores sobre o CA para a espécie $E$. grandis. No que diz respeito à madeira da espécie de T. rubrivenium, apenas o fator tratamento e a interação entre os fatores ciclo e tratamento apresentaram significância. Todos os acabamentos tornaram a superfície da madeira mais hidrofóbica em relação àquelas sem acabamento.

Os revestimentos aplicados, especialmente na madeira de T. rubrivenium, tornaram a superfície mais hidrofóbica. No entanto, a exposição ao envelhecimento acelerado aumentou o grau de molhabilidade das superfícies tratadas. 
Tabela 2. Cinética do comportamento das coordenadas cromáticas $\left(\mathrm{a}^{*}, \mathrm{~b}^{*}\right.$ e $\left.\mathrm{L}^{*}\right)$ ao longo do período de exposição ao intemperismo artificial nas madeiras revestidas e não revestidas com os produtos de acabamento.

Table 2. Kinetics of the behavior of the chromatic coordinates $\left(\mathrm{a}^{*}, \mathrm{~b}^{*}\right.$ and $\left.\mathrm{L}^{*}\right)$ over the period of exposure to artificial weathering in coated and uncoated woods.

\begin{tabular}{|c|c|c|c|c|c|c|c|c|c|c|c|c|c|}
\hline \multicolumn{14}{|c|}{$a^{*}$} \\
\hline \multirow{2}{*}{ Tratamento } & \multirow{2}{*}{ Espécie } & \multicolumn{12}{|c|}{ Tempo de exposição (h) } \\
\hline & & 0 & 12 & 24 & 36 & 48 & 60 & 72 & 96 & 120 & 240 & 360 & 480 \\
\hline \multirow{2}{*}{ T0 } & E. grandis & $\begin{array}{l}10,18 \\
(0,77)\end{array}$ & $\begin{array}{l}11,20 \\
(1,74)\end{array}$ & $\begin{array}{l}10,07 \\
(1,27)\end{array}$ & $\begin{array}{l}10,32 \\
(1,52)\end{array}$ & $\begin{array}{c}9,46 \\
(1,27)\end{array}$ & $\begin{array}{c}9,38 \\
(1,29)\end{array}$ & $\begin{array}{c}9,64 \\
(1,46)\end{array}$ & $\begin{array}{c}8,93 \\
(1,13)\end{array}$ & $\begin{array}{c}7,71 \\
(0,93)\end{array}$ & $\begin{array}{c}6,13 \\
(0,85)\end{array}$ & $\begin{array}{c}4,89 \\
(0,74)\end{array}$ & $\begin{array}{c}4,18 \\
(0,64)\end{array}$ \\
\hline & T. rubrivenium & $\begin{array}{l}-0,01 \\
(0,24)\end{array}$ & $\begin{array}{c}4,47 \\
(0,28)\end{array}$ & $\begin{array}{c}5,34 \\
(0,35) \\
\end{array}$ & $\begin{array}{c}5,86 \\
(0,33) \\
\end{array}$ & $\begin{array}{c}6,51 \\
(0,36) \\
\end{array}$ & $\begin{array}{c}6,68 \\
(0,34) \\
\end{array}$ & $\begin{array}{c}7,34 \\
(0,32) \\
\end{array}$ & $\begin{array}{c}7,69 \\
(0,33) \\
\end{array}$ & $\begin{array}{c}7,48 \\
(0,36) \\
\end{array}$ & $\begin{array}{c}7,26 \\
(0,45) \\
\end{array}$ & $\begin{array}{c}6,72 \\
(0,43) \\
\end{array}$ & $\begin{array}{r}6,24 \\
(0,46) \\
\end{array}$ \\
\hline \multirow{2}{*}{$\mathrm{T} 1$} & E. grandis & $\begin{array}{l}14,25 \\
(1,76)\end{array}$ & $\begin{array}{l}15,05 \\
(2,01)\end{array}$ & $\begin{array}{l}15,21 \\
(2,13)\end{array}$ & $\begin{array}{l}15,45 \\
(2,17)\end{array}$ & $\begin{array}{l}15,56 \\
(2,19)\end{array}$ & $\begin{array}{l}15,92 \\
(2,27)\end{array}$ & $\begin{array}{l}16,20 \\
(2,29)\end{array}$ & $\begin{array}{l}16,33 \\
(2,26)\end{array}$ & $\begin{array}{l}16,44 \\
(2,16)\end{array}$ & $\begin{array}{l}16,29 \\
(1,89)\end{array}$ & $\begin{array}{l}15,81 \\
(1,57)\end{array}$ & $\begin{array}{l}15,41 \\
(1,29)\end{array}$ \\
\hline & T. rubrivenium & $\begin{array}{l}11,36 \\
(0,88) \\
\end{array}$ & $\begin{array}{l}11,95 \\
(0,74) \\
\end{array}$ & $\begin{array}{l}12,08 \\
(0,69) \\
\end{array}$ & $\begin{array}{l}12,31 \\
(0,80) \\
\end{array}$ & $\begin{array}{l}12,47 \\
(0,63) \\
\end{array}$ & $\begin{array}{l}12,45 \\
(0,71) \\
\end{array}$ & $\begin{array}{l}12,70 \\
(0,61) \\
\end{array}$ & $\begin{array}{l}12,85 \\
(0,65) \\
\end{array}$ & $\begin{array}{l}13,16 \\
(0,63) \\
\end{array}$ & $\begin{array}{l}13,47 \\
(0,50) \\
\end{array}$ & $\begin{array}{l}14,05 \\
(0,39)\end{array}$ & $\begin{array}{l}14,27 \\
(0,32) \\
\end{array}$ \\
\hline \multirow{2}{*}{$\mathrm{T} 2$} & E. grandis & $\begin{array}{l}13,21 \\
(1,61)\end{array}$ & $\begin{array}{l}15,77 \\
(1,90)\end{array}$ & $\begin{array}{l}16,39 \\
(2,00)\end{array}$ & $\begin{array}{l}16,45 \\
(1,97)\end{array}$ & $\begin{array}{l}16,64 \\
(2,04)\end{array}$ & $\begin{array}{l}17,15 \\
(1,87)\end{array}$ & $\begin{array}{l}17,44 \\
(2,02)\end{array}$ & $\begin{array}{l}17,44 \\
(1,96)\end{array}$ & $\begin{array}{l}17,98 \\
(2,01)\end{array}$ & $\begin{array}{l}17,70 \\
(1,72)\end{array}$ & $\begin{array}{l}17,65 \\
(1,82)\end{array}$ & $\begin{array}{l}17,57 \\
(1,86)\end{array}$ \\
\hline & T. rubrivenium & $\begin{array}{c}1,76 \\
(0,078) \\
\end{array}$ & $\begin{array}{c}6,91 \\
(0,60) \\
\end{array}$ & $\begin{array}{c}8,15 \\
(0,49) \\
\end{array}$ & $\begin{array}{c}9,04 \\
(0,65) \\
\end{array}$ & $\begin{array}{c}9,90 \\
(0,74) \\
\end{array}$ & $\begin{array}{l}10,33 \\
(0,73) \\
\end{array}$ & $\begin{array}{r}10,80 \\
(0,75) \\
\end{array}$ & $\begin{array}{r}11,78 \\
(0,60) \\
\end{array}$ & $\begin{array}{l}12,41 \\
(0,59) \\
\end{array}$ & $\begin{array}{l}14,37 \\
(0,72) \\
\end{array}$ & $\begin{array}{l}14,73 \\
(0,65) \\
\end{array}$ & $\begin{array}{r}15,41 \\
(0,67) \\
\end{array}$ \\
\hline \multirow[b]{2}{*}{$\mathrm{T} 3$} & E. grandis & $\begin{array}{c}2,03 \\
(0,24)\end{array}$ & $\begin{array}{c}2,08 \\
(0,39)\end{array}$ & $\begin{array}{c}2,15 \\
(0,36)\end{array}$ & $\begin{array}{c}1,98 \\
(0,39)\end{array}$ & $\begin{array}{c}1,91 \\
(0,39)\end{array}$ & $\begin{array}{c}2,21 \\
(0,41)\end{array}$ & $\begin{array}{c}2,13 \\
(0,42)\end{array}$ & $\begin{array}{c}1,92 \\
(0,41)\end{array}$ & $\begin{array}{c}2,04 \\
(0,44)\end{array}$ & $\begin{array}{c}1,98 \\
(0,42)\end{array}$ & $\begin{array}{c}1,78 \\
(0,43)\end{array}$ & $\begin{array}{c}1,77 \\
(0,40)\end{array}$ \\
\hline & T. rubrivenium & $\begin{array}{c}0,65 \\
(0,25) \\
\end{array}$ & $\begin{array}{c}0,99 \\
(0,22) \\
\end{array}$ & $\begin{array}{c}1,18 \\
(0,19) \\
\end{array}$ & $\begin{array}{c}1,02 \\
(0,20) \\
\end{array}$ & $\begin{array}{c}1,04 \\
(0,20) \\
\end{array}$ & $\begin{array}{c}1,26 \\
(0,20) \\
\end{array}$ & $\begin{array}{c}1,39 \\
(0,21) \\
\end{array}$ & $\begin{array}{c}1,16 \\
(0,21) \\
\end{array}$ & $\begin{array}{c}1,23 \\
(0,21) \\
\end{array}$ & $\begin{array}{c}1,41 \\
(0,23) \\
\end{array}$ & $\begin{array}{c}1,45 \\
(0,24) \\
\end{array}$ & $\begin{array}{c}1,58 \\
(0,26) \\
\end{array}$ \\
\hline $\mathrm{T} 4$ & E. grandis & $\begin{array}{c}0,76 \\
(0,21) \\
0,65 \\
(0,15) \\
\end{array}$ & $\begin{array}{c}0,81 \\
(0,22) \\
0,88 \\
(0,12) \\
\end{array}$ & $\begin{array}{c}0,86 \\
(0,19) \\
1,12 \\
(0,13) \\
\end{array}$ & $\begin{array}{c}0,68 \\
(0,18) \\
0,91 \\
(0,14) \\
\end{array}$ & $\begin{array}{c}0,66 \\
(0,18) \\
0,88 \\
(0,12) \\
\end{array}$ & $\begin{array}{c}0,97 \\
(0,19) \\
1,09 \\
(0,12) \\
\end{array}$ & $\begin{array}{c}1,31 \\
(2,28) \\
1,21 \\
(0,12) \\
\end{array}$ & $\begin{array}{c}0,65 \\
(0,19) \\
0,94 \\
(0,12) \\
\end{array}$ & $\begin{array}{c}0,76 \\
(0,18) \\
1,02 \\
(0,12) \\
\end{array}$ & $\begin{array}{c}0,72 \\
(0,19) \\
1,15 \\
(0,14) \\
\end{array}$ & $\begin{array}{c}0,54 \\
(0,20) \\
1,01 \\
(0,13) \\
\end{array}$ & $\begin{array}{c}0,54 \\
(0,18) \\
1,08 \\
(0,13) \\
\end{array}$ \\
\hline \multicolumn{14}{|c|}{$b^{*}$} \\
\hline T0 & $\begin{array}{l}\text { E. grandis } \\
\text { T. rubrivenium }\end{array}$ & $\begin{array}{l}18,72 \\
(1,13) \\
28,08 \\
(0,93)\end{array}$ & $\begin{array}{l}26,26 \\
(1,92) \\
33,68 \\
(0,66) \\
\end{array}$ & $\begin{array}{l}25,51 \\
(1,07) \\
33,61 \\
(0,73) \\
\end{array}$ & $\begin{array}{l}26,05 \\
(1,25) \\
34,07 \\
(0,93) \\
\end{array}$ & $\begin{array}{l}25,27 \\
(1,01) \\
33,93 \\
(1,03) \\
\end{array}$ & $\begin{array}{l}24,41 \\
(1,04) \\
33,26 \\
(0,94) \\
\end{array}$ & $\begin{array}{l}24,13 \\
(1,37) \\
33,81 \\
(1,05) \\
\end{array}$ & $\begin{array}{l}22,59 \\
(1,19) \\
33,68 \\
(1,23) \\
\end{array}$ & $\begin{array}{l}20,68 \\
(1,28) \\
32,27 \\
(1,03) \\
\end{array}$ & $\begin{array}{l}16,14 \\
(2,06) \\
28,65 \\
(1,27) \\
\end{array}$ & $\begin{array}{l}13,79 \\
(2,15) \\
25,53 \\
(1,14) \\
\end{array}$ & $\begin{array}{l}11,93 \\
(2,17) \\
23,03 \\
(1,08)\end{array}$ \\
\hline \multirow{2}{*}{$\mathrm{T} 1$} & E. grandis & $\begin{array}{l}38,62 \\
(2,15)\end{array}$ & $\begin{array}{l}36,09 \\
(2,38)\end{array}$ & $\begin{array}{l}35,44 \\
(2,73)\end{array}$ & $\begin{array}{l}35,21 \\
(2,83)\end{array}$ & $\begin{array}{l}35,00 \\
(3,07)\end{array}$ & $\begin{array}{l}34,71 \\
(3,30)\end{array}$ & $\begin{array}{l}34,79 \\
(3,40)\end{array}$ & $\begin{array}{l}34,59 \\
(3,60)\end{array}$ & $\begin{array}{l}34,08 \\
(3,65)\end{array}$ & $\begin{array}{l}32,69 \\
(4,30)\end{array}$ & $\begin{array}{l}32,12 \\
(4,53)\end{array}$ & $\begin{array}{l}31,51 \\
(4,63)\end{array}$ \\
\hline & T. rubrivenium & $\begin{array}{l}51,86 \\
(2,00) \\
\end{array}$ & $\begin{array}{l}49,40 \\
(2,00) \\
\end{array}$ & $\begin{array}{l}48,61 \\
(2,40) \\
\end{array}$ & $\begin{array}{l}48,22 \\
(1,75) \\
\end{array}$ & $\begin{array}{l}48,47 \\
(2,49) \\
\end{array}$ & $\begin{array}{l}47,98 \\
(2,29) \\
\end{array}$ & $\begin{array}{l}47,97 \\
(2,31) \\
\end{array}$ & $\begin{array}{l}47,91 \\
(2,26) \\
\end{array}$ & $\begin{array}{l}47,45 \\
(2,15) \\
\end{array}$ & $\begin{array}{l}46,60 \\
(2,29) \\
\end{array}$ & $\begin{array}{l}45,87 \\
(2,17) \\
\end{array}$ & $\begin{array}{l}45,54 \\
(2,07) \\
\end{array}$ \\
\hline \multirow{2}{*}{$\mathrm{T} 2$} & E. grandis & $\begin{array}{l}28,92 \\
(1,56)\end{array}$ & $\begin{array}{l}33,22 \\
(1,69)\end{array}$ & $\begin{array}{l}34,54 \\
(1,71)\end{array}$ & $\begin{array}{l}35,14 \\
(1,80)\end{array}$ & $\begin{array}{l}36,08 \\
(1,72)\end{array}$ & $\begin{array}{l}36,70 \\
(1,78)\end{array}$ & $\begin{array}{l}37,19 \\
(1,76)\end{array}$ & $\begin{array}{l}38,01 \\
(1,82)\end{array}$ & $\begin{array}{l}38,86 \\
(1,87)\end{array}$ & $\begin{array}{l}39,50 \\
(2,03)\end{array}$ & $\begin{array}{l}39,80 \\
(2,27)\end{array}$ & $\begin{array}{l}39,73 \\
(2,42)\end{array}$ \\
\hline & T. rubrivenium & $\begin{array}{l}41,03 \\
(1,85) \\
\end{array}$ & $\begin{array}{l}42,59 \\
(1,41) \\
\end{array}$ & $\begin{array}{l}43,22 \\
(1,14) \\
\end{array}$ & $\begin{array}{l}45,02 \\
(1,04) \\
\end{array}$ & $\begin{array}{l}46,02 \\
(1,13) \\
\end{array}$ & $\begin{array}{l}46,05 \\
(0,96) \\
\end{array}$ & $\begin{array}{l}46,38 \\
(1,29) \\
\end{array}$ & $\begin{array}{l}48,71 \\
(1,02) \\
\end{array}$ & $\begin{array}{l}49,20 \\
(0,86) \\
\end{array}$ & $\begin{array}{r}49,87 \\
(0,71) \\
\end{array}$ & $\begin{array}{r}49,61 \\
(0,95) \\
\end{array}$ & $\begin{array}{l}49,98 \\
(1,08) \\
\end{array}$ \\
\hline \multirow{2}{*}{$\mathrm{T} 3$} & E. grandis & $\begin{array}{c}0,62 \\
(0,25)\end{array}$ & $\begin{array}{c}0,82 \\
(0,74)\end{array}$ & $\begin{array}{c}0,57 \\
(0,74)\end{array}$ & $\begin{array}{c}0,74 \\
(0,76)\end{array}$ & $\begin{array}{c}0,72 \\
(0,75)\end{array}$ & $\begin{array}{c}0,47 \\
(0,78)\end{array}$ & $\begin{array}{c}0,47 \\
(0,80)\end{array}$ & $\begin{array}{c}0,55 \\
(0,81)\end{array}$ & $\begin{array}{c}0,51 \\
(0,77)\end{array}$ & $\begin{array}{c}0,20 \\
(0,85)\end{array}$ & $\begin{array}{c}0,15 \\
(0,88)\end{array}$ & $\begin{array}{c}0,04 \\
(0,90)\end{array}$ \\
\hline & T. rubrivenium & $\begin{array}{c}3,63 \\
(0,41) \\
\end{array}$ & $\begin{array}{c}3,65 \\
(0,64) \\
\end{array}$ & $\begin{array}{c}3,56 \\
(0,37) \\
\end{array}$ & $\begin{array}{c}3,70 \\
(0,34) \\
\end{array}$ & $\begin{array}{c}3,77 \\
(0,34) \\
\end{array}$ & $\begin{array}{c}3,61 \\
(0,35) \\
\end{array}$ & $\begin{array}{c}3,40 \\
(0,36) \\
\end{array}$ & $\begin{array}{c}3,65 \\
(0,37) \\
\end{array}$ & $\begin{array}{c}3,61 \\
(0,37) \\
\end{array}$ & $\begin{array}{c}3,41 \\
(0,36) \\
\end{array}$ & $\begin{array}{c}3,25 \\
(0,35) \\
\end{array}$ & $\begin{array}{c}3,19 \\
(0,37)\end{array}$ \\
\hline $\mathrm{T} 4$ & E. grandis & $\begin{array}{c}-1,66 \\
(0,38) \\
0,87 \\
(0,28) \\
\end{array}$ & $\begin{array}{c}-1,45 \\
(0,28) \\
0,91 \\
(0,35) \\
\end{array}$ & $\begin{array}{c}-1,62 \\
(0,29) \\
0,68 \\
(0,39) \\
\end{array}$ & $\begin{array}{c}-1,36 \\
(0,28) \\
0,95 \\
(0,37) \\
\end{array}$ & $\begin{array}{c}-1,41 \\
(0,30) \\
0,99 \\
(0,31) \\
\end{array}$ & $\begin{array}{c}-1,73 \\
(0,30) \\
0,79 \\
(0,36) \\
\end{array}$ & $\begin{array}{c}-1,71 \\
(0,33) \\
0,57 \\
(0,33) \\
\end{array}$ & $\begin{array}{c}-1,57 \\
(0,33) \\
0,87 \\
(0,27) \\
\end{array}$ & $\begin{array}{c}-1,59 \\
(0,30) \\
0,84 \\
(0,28) \\
\end{array}$ & $\begin{array}{c}-1,76 \\
(0,38) \\
0,61 \\
(0,27) \\
\end{array}$ & $\begin{array}{c}-1,66 \\
(0,39) \\
0,64 \\
(0,25) \\
\end{array}$ & $\begin{array}{c}-1,60 \\
(0,42) \\
0,61 \\
(0,27) \\
\end{array}$ \\
\hline \multicolumn{14}{|c|}{$L^{*}$} \\
\hline \multirow{2}{*}{ T0 } & E. grandis & $\begin{array}{l}75,61 \\
(1,97)\end{array}$ & $\begin{array}{l}68,22 \\
(2,89)\end{array}$ & $\begin{array}{l}66,57 \\
(2,68)\end{array}$ & $\begin{array}{l}66,17 \\
(2,93)\end{array}$ & $\begin{array}{l}65,41 \\
(2,91)\end{array}$ & $\begin{array}{l}65,63 \\
(3,03)\end{array}$ & $\begin{array}{l}66,01 \\
(3,21)\end{array}$ & $\begin{array}{l}67,23 \\
(2,97)\end{array}$ & $\begin{array}{l}66,69 \\
(2,96)\end{array}$ & $\begin{array}{l}69,89 \\
(3,44)\end{array}$ & $\begin{array}{l}72,14 \\
(3,44)\end{array}$ & $\begin{array}{l}74,18 \\
(3,36)\end{array}$ \\
\hline & T. rubrivenium & $\begin{array}{l}86,24 \\
(0,54)\end{array}$ & $\begin{array}{l}79,49 \\
(0,62)\end{array}$ & $\begin{array}{l}76,48 \\
(1,19)\end{array}$ & $\begin{array}{l}75,80 \\
(0,89)\end{array}$ & $\begin{array}{l}75,52 \\
(0,93)\end{array}$ & $\begin{array}{l}73,63 \\
(0,68)\end{array}$ & $\begin{array}{l}74,01 \\
(0,85)\end{array}$ & $\begin{array}{l}73,60 \\
(0,86)\end{array}$ & $\begin{array}{l}72,05 \\
(0,71)\end{array}$ & $\begin{array}{l}71,73 \\
(0,85)\end{array}$ & $\begin{array}{l}72,07 \\
(0,87)\end{array}$ & $\begin{array}{l}73,43 \\
(0,94)\end{array}$ \\
\hline \multirow{2}{*}{$\mathrm{T} 1$} & E. grandis & $\begin{array}{l}60,44 \\
(2,41)\end{array}$ & $\begin{array}{l}56,36 \\
(2,94)\end{array}$ & $\begin{array}{l}55,44 \\
(3,36)\end{array}$ & $\begin{array}{l}54,95 \\
(3,25)\end{array}$ & $\begin{array}{l}54,43 \\
(3,41)\end{array}$ & $\begin{array}{l}54,08 \\
(3,61)\end{array}$ & $\begin{array}{l}53,98 \\
(3,72)\end{array}$ & $\begin{array}{l}53,57 \\
(3,73)\end{array}$ & $\begin{array}{l}53,12 \\
(3,68)\end{array}$ & $\begin{array}{l}52,26 \\
(3,90)\end{array}$ & $\begin{array}{l}51,82 \\
(3,93)\end{array}$ & $\begin{array}{l}51,86 \\
(3,84)\end{array}$ \\
\hline & T. rubrivenium & $\begin{array}{l}64,21 \\
(2,16) \\
\end{array}$ & $\begin{array}{l}62,74 \\
(2,63) \\
\end{array}$ & $\begin{array}{r}62,46 \\
(1,96) \\
\end{array}$ & $\begin{array}{r}61,95 \\
(2,74) \\
\end{array}$ & $\begin{array}{l}62,07 \\
(2,46) \\
\end{array}$ & $\begin{array}{c}61,83 \\
(2,68) \\
\end{array}$ & $\begin{array}{r}61,67 \\
(2,49) \\
\end{array}$ & $\begin{array}{r}61,44 \\
(2,57) \\
\end{array}$ & $\begin{array}{l}61,18 \\
(2,48) \\
\end{array}$ & $\begin{array}{r}60,75 \\
(2,56) \\
\end{array}$ & $\begin{array}{r}60,10 \\
(2,29) \\
\end{array}$ & $\begin{array}{l}60,22 \\
(2,01)\end{array}$ \\
\hline \multirow{2}{*}{$\mathrm{T} 2$} & E. grandis & $\begin{array}{l}70,57 \\
(2,61)\end{array}$ & $\begin{array}{l}63,80 \\
(2,76)\end{array}$ & $\begin{array}{l}62,50 \\
(2,69)\end{array}$ & $\begin{array}{l}61,94 \\
(2,78)\end{array}$ & $\begin{array}{l}61,09 \\
(2,85)\end{array}$ & $\begin{array}{l}60,68 \\
(2,59)\end{array}$ & $\begin{array}{l}60,24 \\
(2,83)\end{array}$ & $\begin{array}{l}59,88 \\
(2,74)\end{array}$ & $\begin{array}{l}59,58 \\
(2,79)\end{array}$ & $\begin{array}{l}59,07 \\
(2,80)\end{array}$ & $\begin{array}{l}58,62 \\
(3,16)\end{array}$ & $\begin{array}{l}58,87 \\
(3,41)\end{array}$ \\
\hline & T. rubrivenium & $\begin{array}{l}81,68 \\
(1,36) \\
\end{array}$ & $\begin{array}{l}76,11 \\
(1,05) \\
\end{array}$ & $\begin{array}{r}74,58 \\
(0,90) \\
\end{array}$ & $\begin{array}{r}73,31 \\
(1,14) \\
\end{array}$ & $\begin{array}{r}72,83 \\
(1,21) \\
\end{array}$ & $\begin{array}{r}71,92 \\
(1,31) \\
\end{array}$ & $\begin{array}{r}71,46 \\
(1,17) \\
\end{array}$ & $\begin{array}{r}70,94 \\
(1,00) \\
\end{array}$ & $\begin{array}{r}70,03 \\
(1,13) \\
\end{array}$ & $\begin{array}{r}67,87 \\
(1,25) \\
\end{array}$ & $\begin{array}{r}67,34 \\
(1,32) \\
\end{array}$ & $\begin{array}{l}67,15 \\
(1,36) \\
\end{array}$ \\
\hline \multirow{2}{*}{$\mathrm{T} 3$} & E. grandis & $\begin{array}{l}90,52 \\
(0,73)\end{array}$ & $\begin{array}{l}89,73 \\
(0,84)\end{array}$ & $\begin{array}{l}89,70 \\
(0,92)\end{array}$ & $\begin{array}{l}89,80 \\
(0,91)\end{array}$ & $\begin{array}{l}89,68 \\
(0,90)\end{array}$ & $\begin{array}{l}89,28 \\
(0,98)\end{array}$ & $\begin{array}{l}89,24 \\
(0,99)\end{array}$ & $\begin{array}{l}89,22 \\
(1,06)\end{array}$ & $\begin{array}{l}89,21 \\
(1,10)\end{array}$ & $\begin{array}{l}88,91 \\
(1,13)\end{array}$ & $\begin{array}{l}88,69 \\
(1,17)\end{array}$ & $\begin{array}{l}88,92 \\
(1,19)\end{array}$ \\
\hline & T. rubrivenium & $\begin{array}{l}93,39 \\
(0,46) \\
\end{array}$ & $\begin{array}{r}92,78 \\
(0,64) \\
\end{array}$ & $\begin{array}{l}92,47 \\
(0,63) \\
\end{array}$ & $\begin{array}{l}92,62 \\
(0,62) \\
\end{array}$ & $\begin{array}{l}92,77 \\
(0,59) \\
\end{array}$ & $\begin{array}{r}92,38 \\
(0,61) \\
\end{array}$ & $\begin{array}{l}92,14 \\
(0,70) \\
\end{array}$ & $\begin{array}{r}92,40 \\
(0,55) \\
\end{array}$ & $\begin{array}{r}92,30 \\
(0,51) \\
\end{array}$ & $\begin{array}{r}91,98 \\
(0,47) \\
\end{array}$ & $\begin{array}{l}91,88 \\
(0,52) \\
\end{array}$ & $\begin{array}{r}92,06 \\
(0,58) \\
\end{array}$ \\
\hline \multirow{2}{*}{$\mathrm{T} 4$} & E. grandis & $\begin{array}{l}92,95 \\
(0,80)\end{array}$ & $\begin{array}{l}91,80 \\
(0,98)\end{array}$ & $\begin{array}{l}91,41 \\
(1,07)\end{array}$ & $\begin{array}{l}91,89 \\
(0,94)\end{array}$ & $\begin{array}{l}91,92 \\
(0,96)\end{array}$ & $\begin{array}{l}91,55 \\
(0,98)\end{array}$ & $\begin{array}{l}91,58 \\
(1,02)\end{array}$ & $\begin{array}{l}91,60 \\
(0,92)\end{array}$ & $\begin{array}{l}91,58 \\
(0,95)\end{array}$ & $\begin{array}{l}91,46 \\
(0,96)\end{array}$ & $\begin{array}{l}91,38 \\
(0,93)\end{array}$ & $\begin{array}{l}91,77 \\
(0,96)\end{array}$ \\
\hline & T. rubrivenium & $\begin{array}{l}95,26 \\
(0,29) \\
\end{array}$ & $\begin{array}{r}94,69 \\
(0,38) \\
\end{array}$ & $\begin{array}{r}94,33 \\
(0,47) \\
\end{array}$ & $\begin{array}{r}94,64 \\
(0,39) \\
\end{array}$ & $\begin{array}{l}94,84 \\
(0,36) \\
\end{array}$ & $\begin{array}{r}94,46 \\
(0,38) \\
\end{array}$ & $\begin{array}{r}94,34 \\
(0,48) \\
\end{array}$ & $\begin{array}{l}94,31 \\
(0,40) \\
\end{array}$ & $\begin{array}{l}94,29 \\
(0,50) \\
\end{array}$ & $\begin{array}{l}94,22 \\
(0,47) \\
\end{array}$ & $\begin{array}{l}94,22 \\
(0,47) \\
\end{array}$ & $\begin{array}{l}94,53 \\
(0,51) \\
\end{array}$ \\
\hline
\end{tabular}

em que: $\mathrm{T} 0=$ amostras controle; $\mathrm{T} 1=$ amostras revestidas com polistein; $\mathrm{T} 2=$ amostras revestidas com verniz marítimo; $\mathrm{T} 3=$ amostras revestidas com tinta branca base óleo; T4= amostras revestidas tinta branca base água; $a^{*=}$ coordenada cromática vermelho-verde; $b^{*=}$ coordenada cromática amarelo-azul; $L^{*=}$ luminosidade. 


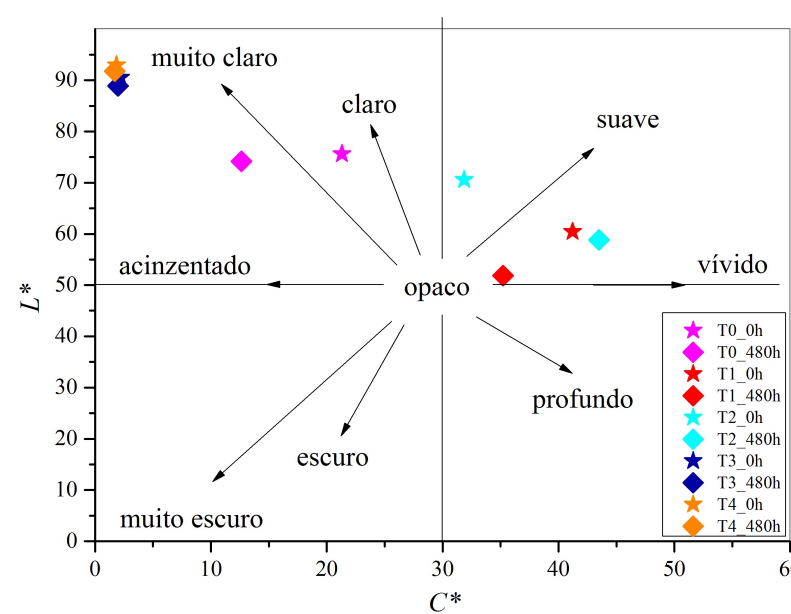

Figura 1. Diagramas de cromaticidade $\left(\mathrm{L}^{*} \mathrm{x} \mathrm{C}^{*}\right)$ para a madeira de E. grandis controle e revestida com produtos de acabamento. Tratamentos: T0 - controle; T1 - polisten; T2 - verniz marítimo; T3 - tinta à base de óleo; $\mathrm{T} 4$ - tinta à base de água.

Figure 1. Chromaticity diagrams $(\mathrm{L} * \mathrm{x} \mathrm{C} *)$ for E. grandis wood control and coated with finishing products. Treatments: T0 - in natura; T1-polisten; T2 - marine varnish; T3 - oil-based paint; T4 water-based paint.

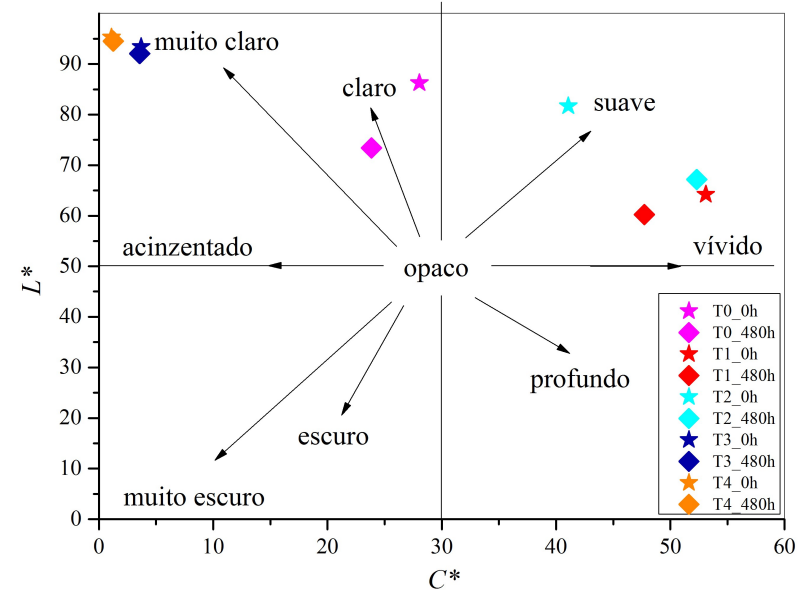

Figura 2. Diagrama de cromaticidade $\left(\mathrm{L}^{*} \mathrm{x} \mathrm{C}^{*}\right)$ para a madeira de $T$. rubrivenium controle e revestida com produtos de acabamento. Tratamentos: T0 - controle; T1 - polisten; T2 - verniz marítimo; T3 - tinta à base de óleo; T4 - tinta à base de água.

Figure 2. Chromaticity diagrams $(\mathrm{L} * \mathrm{x} \mathrm{C} *)$ for $T$. rubrivenium wood control and coated with finishing products. Treatments: T0 in natura; T1-polisten; T2 - marine varnish; T3 - oil-based paint; T4 - water-based paint.

Tabela 3. Análise de variância multifatorial em razão do CA aparente para as duas espécies estudadas.

Table 3. Multivariate analysis of variance for apparent CA of two species studied.

\begin{tabular}{lcccc}
\hline Fonte de Variação & SM & GL & QM & Razão-F \\
\hline \multicolumn{5}{c}{ T. rubrivenium } \\
\hline A:Ciclo & 0,765399 & 1 & 0,765399 & $0,02^{\text {ns }}$ \\
B:Tratamento & 3692,42 & 4 & 923,105 & $20,27^{*}$ \\
A x B & 2840,94 & 4 & 710,234 & $15,60^{*}$ \\
Resíduos & 2732,3 & 60 & 45,5383 \\
\hline \multicolumn{5}{c}{ E. grandis } \\
\hline A:Ciclo & 899,23 & 1 & 899,23 & $19,64^{*}$ \\
B:Tratamento & 2101,13 & 4 & 525,28 & $11,47^{*}$ \\
A x B & 1389,79 & 4 & 347,45 & $7,59^{*}$ \\
Resíduos & 2701,87 & 59 & 45,79 &
\end{tabular}

Em que: $\mathrm{SM}=$ soma dos quadrados; $\mathrm{GL}=$ graus de liberdade; $\mathrm{QM}=$ quadrado médio; $\mathrm{F}=$ valor de $\mathrm{F}$ calculado; ns= não significativo; *= significativo em $5 \%$ de probabilidade de erro.
As madeiras revestidas com os produtos de acabamento T0, T3 e T4 apresentaram um aumento da molhabilidade em solventes polares após $480 \mathrm{~h}$ de exposição. Portanto, dentre todos os tratamentos, o maior aumento da repelência a água na superfície dos materiais revestidos ocorreu para a tinta à base de óleo. Por outro lado, os tratamentos T1 e T2 apresentaram redução no $\mathrm{CA}$ após o mesmo tempo de exposição (Tabela 4).

Tabela 4. Valores médios de CA aparente das madeiras não tratadas e revestidas de $E$. grandis e $T$. rubrivenium.

Table 4. Average values of the apparent CA of untreated and coated E. grandis and T. rubrivenium woods.

\begin{tabular}{|c|c|c|c|c|c|}
\hline \multicolumn{6}{|c|}{ E. grandis } \\
\hline \multicolumn{6}{|c|}{ Tratamentos } \\
\hline $\mathrm{T}$ & T0 & T1 & T2 & T3 & T4 \\
\hline 0 & $\begin{array}{c}71,02 \mathrm{aA} \\
(1,43)\end{array}$ & $\begin{array}{c}80,03 \mathrm{bB} \\
(1,66)\end{array}$ & $\begin{array}{c}79,23 \mathrm{bB} \\
(2,69)\end{array}$ & $\begin{array}{c}86,62 \mathrm{bB} \\
(1,82)\end{array}$ & $\begin{array}{c}63,15 \mathrm{aA} \\
(2,82)\end{array}$ \\
\hline 480 & $\begin{array}{c}\text { 67,31abA } \\
(5,55) \\
\end{array}$ & $\begin{array}{c}71,82 \mathrm{bA} \\
(3,18)\end{array}$ & $\begin{array}{c}58,01 \mathrm{aA} \\
(4,36)\end{array}$ & $\begin{array}{c}76,41 \mathrm{bA} \\
(2,73) \\
\end{array}$ & $\begin{array}{c}69,77 \mathrm{bA} \\
(2,69) \\
\end{array}$ \\
\hline \multicolumn{6}{|c|}{ T. rubrivenium } \\
\hline 0 & $\begin{array}{c}48,20 \mathrm{aA} \\
(1,96)\end{array}$ & $\begin{array}{c}79,78 \mathrm{cB} \\
(1,16)\end{array}$ & $\begin{array}{c}79,45 \mathrm{cB} \\
(3,00)\end{array}$ & $\begin{array}{c}84,63 \mathrm{cA} \\
(2,04)\end{array}$ & $\begin{array}{c}63,98 \mathrm{bA} \\
(0,68)\end{array}$ \\
\hline 480 & $\begin{array}{c}68,1 \mathrm{abB} \\
(3,29)\end{array}$ & $\begin{array}{c}65,27 \mathrm{aA} \\
(3,76)\end{array}$ & $\begin{array}{c}68,92 \mathrm{abA} \\
(4,87)\end{array}$ & $\begin{array}{c}77,64 \mathrm{bA} \\
(3,90)\end{array}$ & $\begin{array}{c}75,03 \mathrm{abB} \\
(1,54)\end{array}$ \\
\hline
\end{tabular}

Ao comparar os diferentes acabamentos ao término do ensaio de envelhecimento acelerado (480h), foi observado para a madeira de $T$. rubrivenium que os revestimentos $\mathrm{T} 0$, T1 e T4 apresentaram valores de CA estatisticamente iguais. Para o E. grandis, T1, T3 e T4 apresentaram o mesmo comportamento, ou seja, não diferiram estatisticamente entre si.

\subsection{Morfologia}

A partir das imagens de alta resolução (Figuras 3 e 4) é possível verificar qualitativamente quais foram os principais efeitos do intemperismo acelerado na madeira de E. grandis e T. rubrivenium em seu estado natural e nos diferentes revestimentos. Os revestimentos comportaram-se de maneira similar para ambas às espécies em todos os tratamentos. Além disso, as modificações na morfologia foram restritas a alterações colorimétricas, pois não foram encontradas micro rachaduras e descascamentos nos revestimentos.

\section{DISCUSSÃO \\ 4.1. Análise colorimétrica}

As principais causas de incremento nas coordenadas $a^{*} \mathrm{e}$ $b^{*}$ das madeiras no T0 estão relacionadas com a migração dos extrativos solúveis em água presentes na superfície da madeira (Tabela 1). A alteração de ambos os parâmetros explica a modificação de tonalidade das madeiras não tratadas. Esse fato pode estar relacionado com a migração de polifenóis para a superfície, que provocam o escurecimento da madeira (MORI et al., 2004). Além disso, a água carrega os extrativos dissolvidos até a superfície da madeira, resultando em manchas amarelas, vermelhas ou marrons após a sua evaporação (WILLAMS, 2010). 
0

T0

$\mathrm{T} 1$

$\mathrm{T} 3$

T4

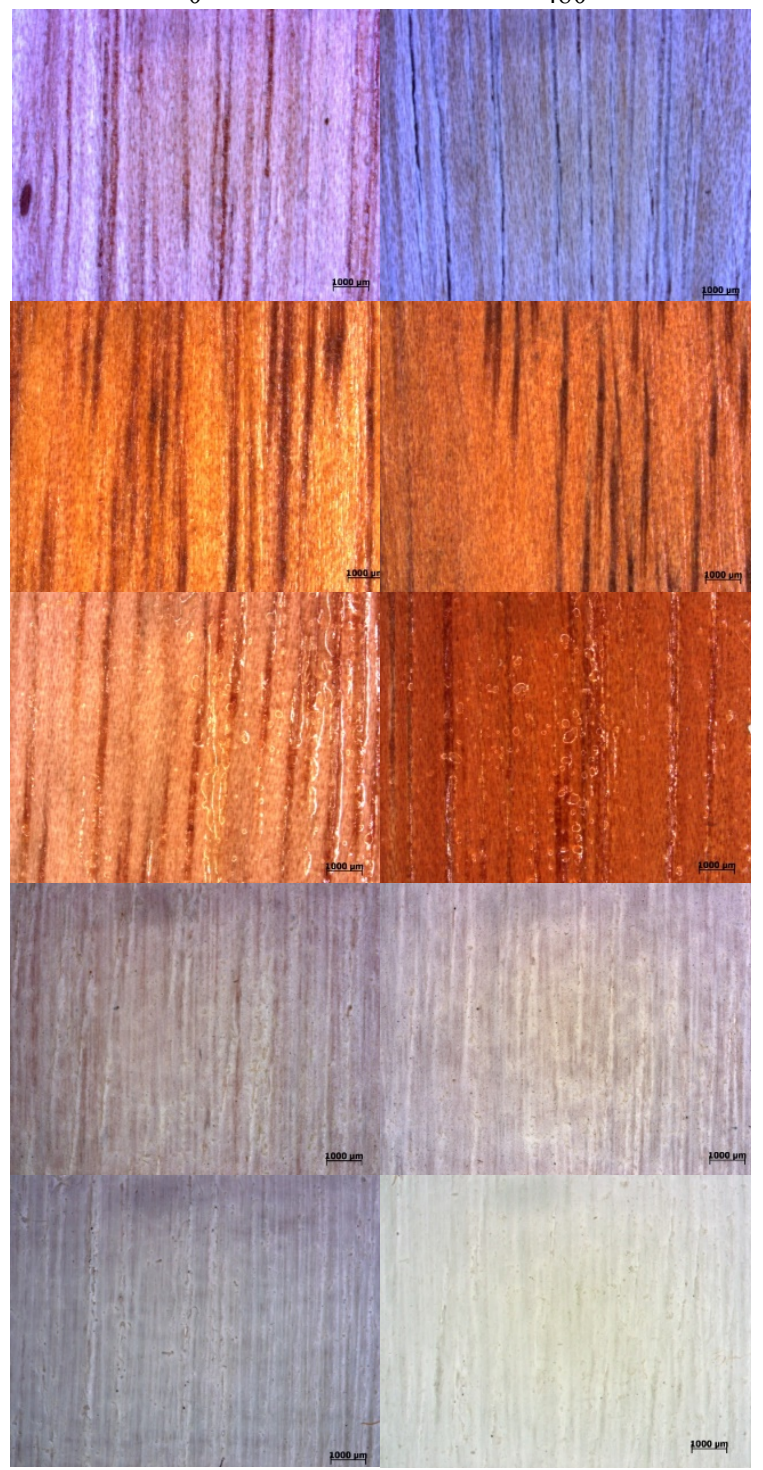

Figura 3. Superfície da madeira de E. grandis antes e após a exposição ao intemperismo acelerado para os diferentes tratamentos (aumento de 10x).

Figure 3. Surface of E. grandis wood before and after exposure to artificial weathering for different treatments (10x).

O escurecimento inicial da madeira se dá devido a decomposição da lignina pela radiação UV na presença de oxigênio. A lignina absorve a luz UV na faixa de 300 a $500 \mathrm{~nm}$, favorecendo a formação de compostos carbonilas insaturados, que promovem a variação de cor da madeira (GRULL et al., 2011; LESAR et al., 2011). Entre todos os revestimentos utilizados, verifica-se que T3 e T4 apresentaram a menor variação de luminosidade superficial no decorrer dos ciclos, o que denota a eficiência desse tipo de revestimento para ambientes externos com incidência direta de luz solar e chuva. Isso ocorre pois os pigmentos presentes na composição química das tintas impedem que a superfície da madeira fique exposta diretamente aos raios UV (WILLIAMS et al., 2010).

Para os tratamentos T0, T1 e T2, houve uma descoloração inicial acentuada. Esse fato está associado a constante exposição das madeiras a elevada umidade do ar, radiação UV. Os compostos de elevado peso molecular e os ácidos orgânicos (vanilina e siringil) são lixiviados provocando alterações na estética da madeira (MATTOS et al., 2014). Já os componentes de baixo peso molecular, tais como os grupamentos carbonila, causam descoloração da madeira ao longo do período de intemperismo (CHANG et al., 2010; YILDIZ et al., 2013; POLETTO, 2017).

Para o revestimento com polistein (T1) verificou-se que a cor da madeira vai perdendo luminosidade durante os ciclos e migra de tons suaves e vívidos para o opaco, especialmente após o ciclo mais drástico de $480 \mathrm{~h}$ de exposição. Por outro lado, o T2 (verniz marítimo) apresentou uma tendência de aumento da vividez e, ao mesmo tempo, perda de suavidade na superfície, indicando que esse revestimento é passível de maior manutenção das características da coloração original das peças com relação aos demais.

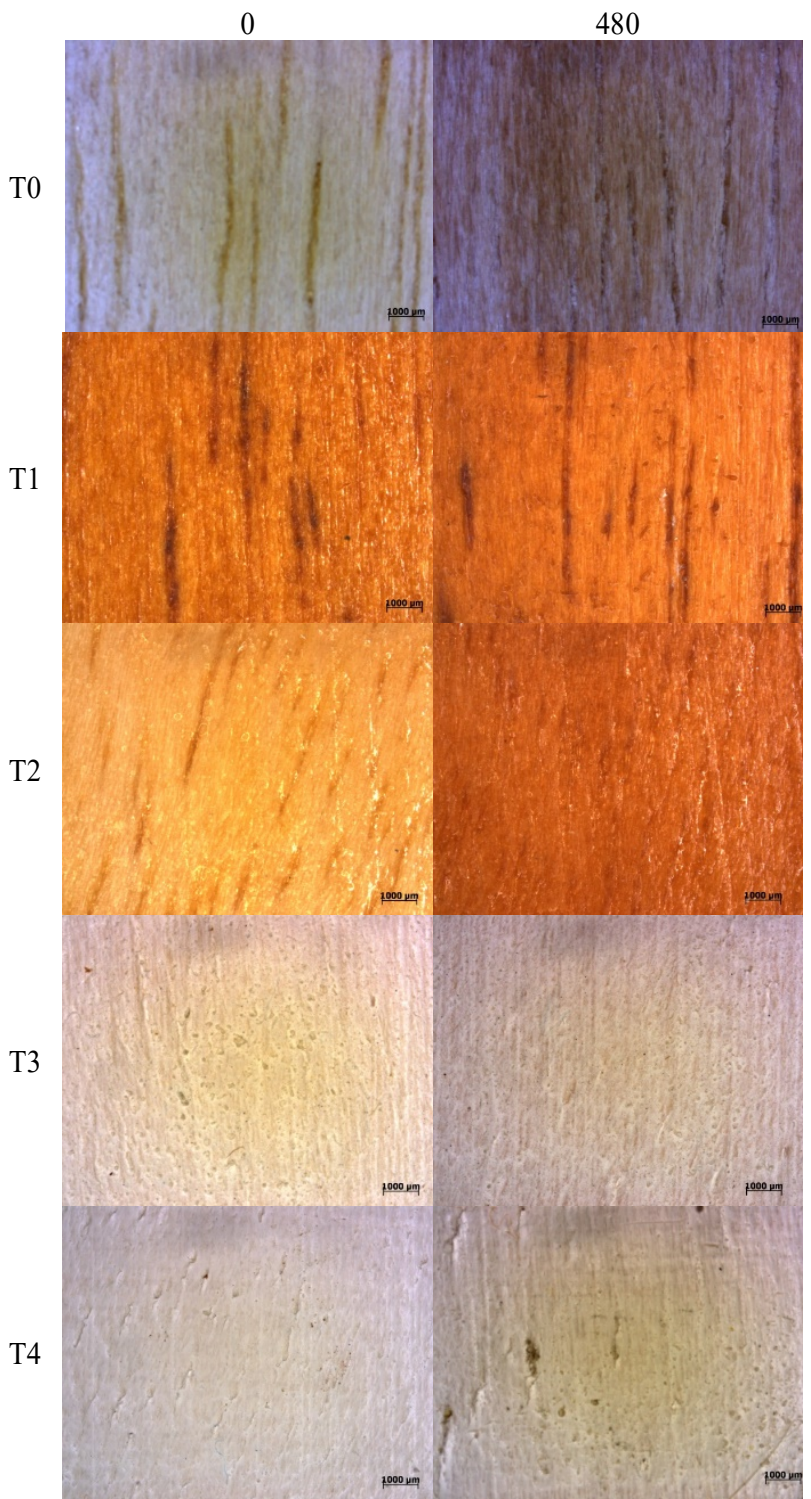

Figura 4. Superfície da madeira de $T$. rubrivenium antes e após a exposição ao intemperismo acelerado para os diferentes tratamentos (aumento de 10x).

Figure 4. Surface of T. rubrivenium wood before and after the exposure to artificial weathering for different treatments $(10 \mathrm{x})$.

\subsection{Molhabilidade}

Os maiores valores de ângulo de contato referem-se a uma superfície mais hidrofóbica. Nesse sentido, para as espécies T. rubrivenium e E. grandis os valores de CA aparente foram inferiores à $90^{\circ}$, o que caracteriza uma superfície hidrofílica (MATTOS et al., 2014). 
Antes da exposição ao intemperismo artificial (0h), tanto a madeira de $T$. rubrivenium, como a madeira E. grandis tratadas com T1, T2 e T3 se comportaram de maneira similar, ou seja, os valores de $\mathrm{CA}$ aparente não diferiram estatisticamente.

Mesmo a madeira de $T$. rubrivenium não apresentando alteração no CA após 480h, verificou-se um pequeno aumento no $\mathrm{CA}$ ao final da exposição. Este aumento do CA pode estar relacionado com a migração de ácidos graxos para a superfície da madeira devido à ação da radiação UV (MARTINS et al., 2011).

Para a madeira de $T$. rubrivenium, verifica-se que o CA entre $0 \mathrm{~h}$ e $480 \mathrm{~h}$ de exposição variou para todos os acabamentos, com exceção do revestimento com tinta à base de óleo. O comportamento do CA em função do ciclo para os acabamentos na madeira de E. grandis foram estatisticamente distintos para polisten, verniz marítimo e tinta à base de óleo. Por outro lado, para a madeira controle e acabamento base de água os níveis não apresentaram variação.

Com exceção de T0 e T4, as demais situações apresentaram uma redução significativa do CA aparente, enfatizando que ao expor a madeira de E. grandis durante $480 \mathrm{~h}$, aumenta-se a molhabilidade superficial. Geralmente, a superfície da madeira em estado natural torna-se mais molhável, devido a superfície resultante do processo de lixiviação dos voláteis provocada pela ação das intempéries apresentar altos teores de celulose com grandes concentrações de grupos carbonilas, carboxilas, quinona, peróxido, e grupos hidroperóxidos (WILLIAMS, 2010).

Na Tabela 2, para os revestimentos T1, T2 e T3, houve redução no CA após as 480h de exposição. Logo, mesmo que a maioria dos revestimentos de uso externo apresente em suas formulações compostos químicos orgânicos que absorvem radiação UV, a ação dos mesmos não é permanente, pois a matriz polimérica do revestimento é degradada pela exposição prolongada da madeira à radiação UV (PICKETT, 2004; CUSTÓDIO; EUSÉBIO, 2006). Além disso, a umidade degrada fisicamente os revestimentos, uma vez que as ligações orgânicas da maioria dos revestimentos sofrem hidrólise, isto é, clivagem das cadeias poliméricas em presença das moléculas de água. Ressalta-se também que esse processo ocorre em todas as temperaturas (NICHOLS, 2005).

\subsection{Morfologia}

Com exceção das superfícies revestidas por T2, os demais tratamentos apresentaram perda de brilho. As superfícies das madeiras tornaram-se opacas após 480h de exposição. Devido ao envelhecimento acelerado, as madeiras das duas espécies com os diferentes revestimentos ficaram com a superfície mais escura em relação ao estado inicial.

Os revestimentos T3 e T4 apresentaram as menores variações na cor. Quanto a ausência de defeitos de superfície, o tempo de exposição de 480h não foi suficiente para que ocorresse o surgimento de micro rachaduras na madeira controle e revestida, bem como descascamento e aparecimento de bolhas nos revestimentos da madeira, diferente do observado por Cademartori et al. (2015) em madeiras sem tratamento superficial. Dessa maneira, as observações qualitativas visualizadas morfologicamente corroboram com a análise colorimétrica.

\section{CONCLUSÕES}

Os diferentes revestimentos aplicados na superfície da madeira de $T$. rubrivenium e E. grandis alteraram suas colorações naturais, tornando-as opacas. A madeira revestida com polisten (T1) e verniz (T2) apresentou menor resistência ao ciclo de exposição de 480 horas. Tintas à base óleo (T3) e a base de água (T4) sofreram pequenas alterações de cor após a exposição para ambas as madeiras. Com exceção do revestimento de tinta base água (T4), os revestimentos não impediram o aumento da molhabilidade da superfície. Por outro lado, os revestimentos aplicados foram eficientes na proteção ao aparecimento de defeitos superficiais, especialmente micro rachaduras e descascamento do filme ao longo do ciclo de $480 \mathrm{~h}$.

\section{AGRADECIMENTOS}

Os autores gostariam de agradecer à Fundação de Amparo à Pesquisa do Rio Grande do Sul (FAPERGS), à Coordenação de Aperfeiçoamento de Pessoal de Nível Superior (CAPES), processo 00.889.834/0001.08, e ao Conselho Nacional de Desenvolvimento Científico e Tecnológico (CNPq), pelo suporte financeiro.

\section{REFERÊNCIAS}

AMERICAN SOCIETY FOR TESTING AND MATERIALS (ASTM). ASTM G 154: Standard practice for operating fluorescent light apparatus for UV exposure of nonmetallic materials. Philadelphia: ASTM, 2006. 4p.

ARANTES, V.; MILAGRES, A. M. F. Relevância de compostos de baixa massa molar produzidos por fungos e envolvidos na biodegradação da madeira. Química Nova, v.32, n.6, p.1586-1595, 2009. DOI: http://dx.doi.org/10.1590/S0100-40422009000600043

CADEMARTORI, P. H. G.; MISSIO, A. L.; MATTOS, B. D. Natural weathering performance of three fast-growing eucalypt woods. Maderas. Ciencia y Tecnologia, v.17, n.4, p.799-808, 2015. http://dx.doi.org/10.4067/S0718-221X2015005000069

CHANG, T. C.; CHANG, H. T.; WU, C. L.; CHANG, S. T. Influences of extractives on the photodegradation of wood. Polymer Degradation and Stability, v.95, n.4, $\begin{array}{lll}\text { p.516-521, } 2010 . & \text { DOI: }\end{array}$ 10.1016/j.polymdegradstab.2009.12.024

CUSTÓDIO, J. E. P.; EUSÉBIO, M. I. Waterborne acrylic varnishes durability on wood. Progress in Organic Coatings, v.56, n.1, p.59-67, 2006. DOI: https://doi.org/10.1016/j.porgcoat.2006.02.008

GRULL, G.; FORSTHUBER, B.; TSCHERNE, F.; SPITALER, I. Weathering indicator for artificial and natural weathering of wood coatings. European Journal Wood Products, v.72, n.5, p.681-684, 2014. DOI: https://doi.org/10.1007/s00107-014-0807-7

GRULL, G.; TRUSKALLER, M.; PODGORSKI, L.; BOLLMUS, S.; TSCHERNE, F. Maintenance procedures and definition of limit states for exterior wood coatings. European Journal Wood Products, v.69, n.3, p.443450, 2011. DOI: 10.1007/s00107-010-0469-z

LESAR, B.; PAVLIC, M.; PETRIC, M.; SKAPIN, A. S.; HUMAR, M. Wax treatment of wood slows photodegradation. Polymer degradation and stability, v.96, n.7, p.1271-1278, 2011. DOI: 10.1016/j.polymdegradstab.2011.04.006 
MARTINS, S. A.; DOS SANTOS, C. M. T.; GONÇALEZ, J C.; CAMARGOS, J. A. A. Envelhecimento artificial acelerado por radiação ultravioleta de madeiras de Eucalyptus benthamii e Pinus caribaea var. hondurensis. Floresta, v.41, n.1, p.87-96, 2011. DOI: http://dx.doi.org/10.5380/rf.v41i1.21185

MATTOS, B. D.; MISSIO, A. L.; CADEMARTORI, P. H. G.; LIMA, E. A.; MAGALHÃES, W. L. E.; GATTO, D. A. Properties of polypropylene composites filled with a mixture of house hold waste of mate-tea and wood particles. Construction and Building Materials, v.61, n.1, p.60-68, 2014. https://doi.org/10.1016/j.conbuildmat. 2014.02.022

MORI, C. L. S. O.; MORI, F. A.; LIMA, J. T.; TRUGILHO, P. F.; OLIVEIRA, A. C. Influência das características tecnológicas na cor da madeira de eucaliptos. Ciência Florestal, v. 14, n. 2, p. 123-132, 2004. DOI: http://dx.doi.org/10.5902/198050981812

NICHOLS, M. E. Paint weathering tests. In: Handbook of Environmental Degradation of Materials. Myer Kutz Associates, Inc. Delmar, New York, 2005, p. 387-404.

OBERHOFNEROVÁ, E.; PÁNEK, M. Surface wetting of selected wood species by water during initial stages of weathering. Wood Research, v. 61, n. 4, p. 545-552, 2016.

PICKETT, J. UV Absorber permanence and coating lifetimes. Journal of Testing and Evaluation, v.32, n.3, p. 240-245, 2004. DOI: https://doi.org/10.1520/JTE11943
POLETTO, M. Comparative study of wood flour photodegradation of two wood species submitted to artificial weathering. Maderas. Ciencia y tecnología, v.19, n.2, p.141-148, 2017. DOI: 10.4067/S0718221X2017005000012

QIAN, Y.; ZHONG, X.; LI, Y.; QIU, X. Fabrication of uniform lignin colloidal spheres for developing natural broad-spectrum sunscreens with high sun protection factor. Industrial Crops and Products, v.101, p.54-60, 2017. DOI: https://doi.org/10.1016/j.indcrop.2017.03.001

ROSU, D.; TEACA, C.A.; BODIRLAU, R.; ROSU, L. FTIR and color change of the modified wood as a result of artificial light irradiation. Journal of Photochemistry and Photobiology B: Biology, v.99, n.3, p.144-149, 2010. DOI: 0.1016/j.jphotobiol.2010.03.010

WILLIAMS, R. Sam. Finishing of Wood. In: Wood handbook-Wood as an engineering material. Centennial Edition. Madison, WI: U.S: General Technical Report FPL-GTR-190, 2010. p.356-394.

YENIOCAK, M.; GOKTAS, O.; COLAK, M.; OZEN, E.; UGURLU, M. 2015. Natural coloration of wood material by red beetroot (Beta vulgaris) and determination color stability under UV exposure. Maderas. Ciencia y tecnología, v.17, n.4, p.711-722, 2015. DOI: 10.4067/S0718-221X2015005000062

YILDIZ, S.; TOMAK, E. D.; YILDIZ, U. C.; USTAOMER, D. Effect of artificial weathering on the properties of heat treated wood. Polymer Degradation and Stability, v.98, n.8, p.1419-1427, 2013. DOI: http://dx.doi.org/10.1016/j.polymdegradstab.2013.05.004 